\title{
Does indigestible food remains in the scats of Sloth Bear Melursus ursinus (Carnivora: Ursidae) represent actual contribution of various diet items?
}

\author{
N. Baskaran ${ }^{1} \&$ Ajay A. Desai ${ }^{2}$ \\ 1,2 Bombay Natural History Society, Elephant Project, Kargudi, The Nilgiris, Tamil Nadu 643211, India \\ ${ }^{1}$ Present address: Asian Nature Conservation Foundation, Innovation Centre, First Floor, Indian Institute of Science, Bengaluru, \\ Karnataka 560012, India \\ ${ }^{2}$ Present address: BC 84 Camp, Belgaum, Karnataka 590001, India \\ Email: ${ }^{1}$ nagarajan.baskaran@gmail.com (corresponding author), ${ }^{2}$ ajayadesai.1@gmail.com
}

\begin{abstract}
The contribution of diet items in the food of sloth bears is estimated solely based on the dry weight or volume of indigestible food remains found in the scats, assuming that the ratio of digestible versus indigestible matters is equal in all diet items. However, this is not true in reality. The implication of this assumption is that the species that contribute a larger bulk of digestible matters are underestimated, while that of less digestible parts get overestimated and consequently are portrayed as important food sources. This study experimentally converts the percent contribution of important fruit items estimated using 'indigestible fruit remains' in the scats into percent contribution by 'digestible fruit content' using known dry weight of digestible fruit contents per volume of indigestible items (estimated using fresh fruit samples from the field). The percent composition of various fruit items obtained using digestible fruit content is significantly different from that derived using indigestible fruit remains in the scats. Future studies could adopt the dry weight of digestible matter as this method estimates the contribution of various food items to the diet of bears more accurately.
\end{abstract}

Keywords: Indigestible and digestible food parts, scat analysis, Sloth Bear diet.

Date of publication (online): 26 December 2010

Date of publication (print): 26 December 2010

ISSN 0974-7907 (online) | 0974-7893 (print)

Editor: C. Srinivasulu

Manuscript details:

Ms \# 02358

Received 08 December 2009

Final received 04 October 2010

Finally accepted 20 November 2010

Citation: Baskaran, N. \& A.A. Desai (2010). Does indigestible food remains in the scats of Sloth Bear Melursus ursinus (Carnivora: Ursidae) represent actual contribution of various diet items? Journal of Threatened Taxa 2(13): 1387-1389.

Copyright: (C) N. Baskaran \& Ajay A. Desai 2010. Creative Commons Attribution 3.0 Unported License. JoTT allows unrestricted use of this article in any medium for non-profit purposes, reproduction and distribution by providing adequate credit to the authors and the source of publication.

Acknowledgements: We thank the Tamil Nadu Forest Department especially Mr. G. Kumaravelu, IFS, the then Conservator of Forests, Wildlife Western Region, Mr. S.K. Srivasthava, IFS, the then Wildlife Warden, Mudumalai Wildlife Sanctuary, for permitting and funding this study. We thank Mr. J.C. Daniel, Honorary Secretary, BNHS, and Dr. A.R. Rahmani, Director, BNHS, for their encouragements and support during the project.

\section{OPEN ACGESS I FREE DOWNLOAD (C) (i) (4)}

Studies on food habits of Sloth Bears Melursus ursinus mostly use scat analysis method (Schaller 1967; Laurie \& Seidensticker 1977; Baskaran 1990; Gokula 1991; Gokula et al. 1995; Baskaran et al. 1995; Desai et al. 1997; Joshi et al. 1997). In this method, the diet composition is arrived at from indigested food remains in the scats using different quantitative measures. Some studies (Schaller 1967) have used percent occurrence of various undigested food remains in the scat, but this does not indicate the quantities consumed. On the other hand, the percent dry weight or percent volume of indigestible food remains technique would ensure better estimation of different food items to the diet. However, the reliability or accuracy of this technique too largely depends on ratio of digestible versus indigestible parts of various food items. Unfortunately, the ratio of digestible versus indigestible parts of food items is not uniform in all food species consumed by bears. For example, Sloth Bears in southern India consume ripe and dried fruits of Cassia fistula. The bears consume the gum-like pulp, which exists between seeds that form less than onethird of the quantity of the total fruit. The remaining parts including seeds and pericarp form more than two-thirds of the total quantum of fruit and are indigestible. Most of the studies (Laurie \& Seidensticker 1977; Baskaran 1990; Gokula 1991; Baskaran et al. 1995; Gokula et al. 1995; Desai et al. 1997; Joshi et al. 1997) that adopt the percent volume or dry weight methods however estimate the relative contribution of various food species merely based on indigestible food remains that appear in the scat by assuming the relative contribution of digestible and indigestible parts equally for all the species. Therefore, species that contribute larger bulk of digestible parts are likely to be underestimated, while those contributing less digestible parts get overestimated, and are consequently portrayed as important food sources of the bears. We therefore carried out an experiment to test the accuracy of using the indigestible food remains in the scat as an indication of relative contribution by various food species to the overall diet of Sloth Bear. This experiment tested only for major fruit species eaten by the bears in 
Mudumalai Wildlife Sanctuary, Tamil Nadu, India.

\section{Methods}

Study area: This experiment was conducted in the tropical forests of Mudumalai Wildlife Sanctuary (presently redesignated as Mudumalai Tiger Reserve).

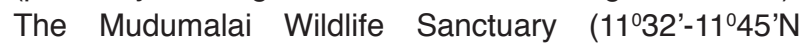
\& $\left.76^{0} 20^{\prime}-76^{\circ} 45^{\prime} E\right)$, located at the tri-junction of three southern states of India, namely Tamil Nadu, Karnataka and Kerala, is a part of the Nilgiri Biosphere Reserve. It is bounded on the north by Bandipur Tiger Reserve in Karnataka, on the west by Wyanad Wildlife Sanctuary in Kerala and on the south and east by Nilgiri North Forest Division in Tamil Nadu. The experiment was carried out between May 1996 and April 1997 as part of a larger study on the behavioural ecology of Sloth Bears (Desai et al. 1997).

Evaluation of food habits: We studied the diet composition and seasonal variation through scat analysis as suggested by earlier studies (Laurie \& Seidensticker 1977; Baskaran 1990; Gokula 1991; Baskaran et al. 1995; Gokula et al. 1995; Desai et al. 1997; Joshi et al. 1997). In the present study, scats were collected along fixed game roads representing different vegetation types at fortnightly intervals. Food items in the scats were segregated by analyzing the entire scat using sieves of different sizes and by hand-sorting. The volume was then estimated to the nearest $1 \mathrm{ml}$ using the water displacement method. Plant matter was identified up to species level using seeds. The animal matter was broadly classified into ants, termites and beetles. Those food items that could not be identified were segregated into unidentified plant and animal matter. The contribution of individual species to the diet was calculated using percent volume method (the total volume individual food item/total volume of all food items $\times 100$ ).

Estimation of digestible and indigestible fruit contents: Based on the fruit remains observed in the scats during the present study $(n=474)$ and the earlier study by Baskaran et al. (1995) ( $n=567)$, important fruit species eaten by Sloth Bears were listed and these include Cassia fistula (17.6\%), Zizyphus mauritiana (15.7\%), Cordia domestica (4.5\%), Grewia tiliifoila $(2.1 \%)$, Z. oenoplia (2.8\%), Lantana camara (1.5\%), and G. hirsuta (0.11). Fresh samples of important fruit species were collected from fruit trees and shrubs representing different habitat/ microhabitat conditions. A total of 15-20 (or in case of tiny fruits like Lantana camara up to 50) fruit samples of various size classes (small, medium and big) and conditions (semi-ripe and ripe in case of $C$. fistula including dry fruits) were collected from multiple plants representing diverse micro- and macro-habitats. The digestible (fruit pulp) and indigestible fruit parts (seeds and pericarp) were separated from each fruit species using a scalpel. The volume of indigestible fruit remains was estimated using the water displacement method and the dry weight of the digestible fruit pulps by using a physical balance after air-drying the samples separately for each fruit species. The indigestible food remains were quantified using the volume displacement method similar to that used to quantify the indigestible food remains from the scat, while the digestible matter was quantified using dry weight method, as this method allowed us to overcome the differential water content in different fruit species. Later, using the details of dry weight of digestible fruit pulp/volume of indigestible food remains, we arrived at the dry weight of the fruit pulp consumed in each species by the bear based on the standard volume of indigestible fruit remains of each species segregated from the scat.

The difference in the contribution of various food items estimated, based on two different methods was tested for statistical significance employing chi-square analysis using the estimated contribution by indigestible fruit remains as the observed value and the estimated contribution by digestible fruit remains as the expected value.

\section{Results}

The percent contribution of various major fruit species, when estimated using the two methods (Table 1), shows a significant difference. For example, during dry season, Cassia fistula drops from being the highest (51.1\%) contributor based on percent volume of indigestible fruit remains moves to the second highest $(30.56 \%)$ position based on dry weight method of digestible fruit remains. Zizyphus mauritiana, on the other hand, moves from the second position (44.1\%) to the first $(57.9 \%)$ on dry weight method of digestible fruit remains. The observed difference in percent contribution of various food items arrived using the two methods varied significantly $\left(X^{2}=24.0\right.$, df $=4, p<$ 0.001 ). Although, during the wet seasons, the ranks do not change between the methods, the relative contributions varied significantly (first wet season $\mathrm{X}^{2}=48.5$; $\mathrm{df}=3$; $\mathrm{p}<$ 0.001 and second wet season $X^{2}=17.8 ; \mathrm{df}=3 ; p<0.01$ ). For example, in the first wet season, the contribution of Cordia domestica to the diet increased from 59.6 to 93.8 $\%$ and that of Grewia tiliifolia dropped from 27.4 to $4.2 \%$ by dry pulp method instead of the percent volume method of indigestible fruit remains. Similarly, in the second wet season, the contribution of $Z$. mauritiana dropped from 25 to $16.36 \%$ while that of $Z$. oenoplia increased from 52.5 to $71 \%$ when the dry pulp method of estimating percent contribution to the diet was used instead of the percent volume indigestible fruit remains method.

\section{Discussion}

The differences between the methods are significant and warrant attention. We feel that the use of digestible food dry weight method is a much better and more accurate method to evaluate the diet of sloth bears. The method basically requires an adequate sample of each diet item be evaluated, to estimate the volume of 
Table 1. Estimating the contribution of fruits of different plant species to the diet of Sloth Bears using the percent volume of seeds (indigestible items) in the scats and the percent dry weight of digestible fruit pulp (estimated from seed volume). For this analysis, the contribution of these food species is treated as $100 \%$ of the diet of the Sloth Bear

\begin{tabular}{|c|c|c|c|c|}
\hline \multirow[b]{2}{*}{ Fruit species } & \multicolumn{2}{|c|}{ Fruit remains calculated from fruit samples } & \multicolumn{2}{|c|}{$\begin{array}{l}\text { Percent contribution to the diet based on two } \\
\text { methods }\end{array}$} \\
\hline & $\begin{array}{l}\text { Volume of indigestible } \\
\text { fruit remains }(\mathrm{cm})\end{array}$ & $\begin{array}{l}\text { Dry weight of digestible } \\
\text { fruit remains }(g)\end{array}$ & $\begin{array}{l}\text { Volume of indigestible } \\
\text { fruit remains in scat } \\
\qquad(\mathrm{cm})\end{array}$ & $\begin{array}{l}\text { Dry weight of digestible } \\
\text { fruit remains }(g)\end{array}$ \\
\hline \multicolumn{5}{|l|}{ Dry season } \\
\hline Grewia hirsuta & 0.07 & 0.01 & 0.32 & 0.34 \\
\hline Cassia fistula & 10.9 & 0.84 & 51.1 & 30.56 \\
\hline Lantana camara & 0.11 & 0.02 & 0.52 & 0.76 \\
\hline Zizyphus mauritiana & 9.48 & 1.6 & 44.1 & 57.95 \\
\hline Zizyphus oenoplia & 0.81 & 0.28 & 3.81 & 10.36 \\
\hline \multicolumn{5}{|l|}{ First wet season } \\
\hline Cordia domestica & 6.56 & 12.6 & 59.6 & 93.82 \\
\hline G. tiliifolia & 3.02 & 0.56 & 27.4 & 4.20 \\
\hline C. fistula & 0.01 & 0 & 0.13 & 0.01 \\
\hline L. camara & 1.4 & 0.26 & 12.7 & 1.96 \\
\hline \multicolumn{5}{|l|}{ Second wet season } \\
\hline C. fistula & 0.22 & 0.01 & 8.66 & 2.6 \\
\hline L. camara & 0.35 & 0.06 & 13.7 & 10.0 \\
\hline Z. mauritiana & 0.64 & 0.10 & 25.0 & 16.4 \\
\hline Z. oenoplia & 1.34 & 0.46 & 52.5 & 71.1 \\
\hline
\end{tabular}

indigestible matter that is required to produce a given dry weight of digestible matter. Once the conversion figures are available, the scats can be analyzed for the volume (indigestible) of different food items and these volumes can later be converted to dry weight of digestible matter using the conversion figures derived earlier. The problem of analyzing the animal matter in a similar fashion also needs to be developed, preferably under captive conditions, whereby it is easy to quantify the digestible versus indigestible matter of insect remains with known quantum of insect food fed to the captive bears and establish a similar conversion figure for various insect foods. In future, the studies on the diet of Sloth Bears (and other species with similar feeding habits) should be analyzed using the dry weight of digestible matter derived from the volume of indigestible matter in the scat, as this will give us a much more accurate means of estimating the contribution of various food items to the diet.

\section{REFERENCES}

Baskaran, N. (1990). An ecological investigation on the dietary composition and habitat utilization of Sloth Bear (Melursus ursinus) at Mudumalai Wildlife Sanctuary, Tamil Nadu (South India). M.Phil. Thesis, A.V.C.College, Mannambandal, Tamil Nadu, India, vi+57pp.

Baskaran, N., N. Sivaganesan \& J. Krishnamoorthy (1997).
Food habits of the Sloth Bear in Mudumalai Wildlife Sanctuary, Tamil Nadu, Southern India. Journal of the Bombay Natural History Society 94(1): 1-9.

Desai, A.A., N. Baskaran \& S. Venkatesh (1997). Behavioural ecology of the Sloth Bear (Melursus ursinus) in Mudumalai Wildlife Sanctuary and National Park, Tamil Nadu. Technical Report. Bombay Natural History Society, Bombay, India

Gokula, V. (1991). Some aspects on the feeding habits of the Sloth Bear (Melursus ursinus) at Mundanthurai Wildlife Sanctuary, Tamil Nadu (South India). M.Sc., Dissertation. A.V.C.College, Mannambandal, Tamil Nadu, India, 48pp.

Gokula, V., N. Sivaganesan \& M. Varadarajan (1995). Food habits of Sloth Bear (Melursus ursinus) in Mundanthurai Pleteau, Tamil Nadu. Journal of the Bombay Natural History Society 92: 408-410.

Joshi, A.R., D.L. Garshelis \& J.L.D. Smith (1997). Seasonal and habitat related diet of Sloth Bears in Nepal: Journal of Mammalogy 78(2): 584-597.

Laurie, A. \& J. Seidensticker (1977). Behavioural ecology of the Sloth Bear (Melursus ursinus). Journal of Zoology London 182: $187-204$.

Schaller, G.B. (1967). The Deer and Tiger: A Study of Wildlife in India. University of Chicago Press, London, viii+370pp. 